\title{
Effects of aqueous extract of garlic (Allium sativum) on the left ventricle myocardium of high salt-fed adult Wistar rats
}

\author{
Olusola S. Saka ${ }^{1}$ A. Omobola Komolafe ${ }^{1}$, Oludare Ogunlade ${ }^{2}$, A. Rotimi Owolabi ${ }^{3}$, \\ Ahmed A. Olayode ${ }^{1}$, Babatunde E. Arayombo ${ }^{1}$ \\ ${ }^{1}$ Department of Anatomy and Cell Biology, Faculty of Basic Medical Sciences, Obafemi Awolowo University, Ile-Ife, Osun-State, Nigeria \\ ${ }^{2}$ Department of Physiological Sciences, Faculty of Basic Medical Sciences, Obafemi Awolowo University, Ile-Ife, Osun-State, Nigeria \\ ${ }^{3}$ Department of Medical Pharmacology and Therapeutics, Faculty of Basic Medical Sciences, Obafemi Awolowo University, Ile-Ife, Osun-State, Nigeria
}

\begin{abstract}
Objectives: The aim of this study was to evaluate the beneficial effect of aqueous extract of garlic (Allium sativum) on the morphology of myocardium of left ventricle in high salt-fed diet Wistar rats.

Methods: Twenty-five female Wistar rats weighing 130-180 g were divided into five groups ( $n=5$, each). Group A were fed with standard laboratory pellets, while Groups B, C, D and E were fed a high-salt diet for five weeks. Following this, daily administration of aqueous garlic extract was done orally to Groups C, D and E, respectively for 3 weeks. The left ventricle of the heart was excised, processed in paraffin wax and stained with haematoxylin and eosin, Masson's trichrome and Verhoeff-Van Gieson stains. One-way ANOVA was used to analyze data, followed by Student-Newman-Keuls (SNK) test for multiple comparisons.

Results: We found that the relative change in heart weight in the high salt-fed group was lower, though not statistically significant $(p=0.175)$ than the control group. There was significant increase $(p<0.05)$ in plasma levels of sodium and potassium in Group B when compared with control, but this was dose-dependently reversed by aqueous garlic extract in Groups $D$ and $E$. Histological and histochemical results revealed morphological alterations in the left ventricle of Group $B$ which were also reversed in Groups D and E.

Conclusion: The results of this study indicate that high salt diet-induced histochemical and histomorphological changes in the left ventricle of Wistar rats were significantly reversed by oral administration of garlic extract.
\end{abstract}

Keywords: garlic; heart; high salt diet; ventricle

Anatomy 2016;10(1):21-29 @2016 Turkish Society of Anatomy and Clinical Anatomy (TSACA)

\section{Introduction}

High salt intake has been reported to promote elevation of blood pressure and cardiovascular changes including left ventricular hypertrophy (LVH), cardiac fibrosis and endothelial dysfunction. ${ }^{[1]}$ Salt overload increases LVH two-fold, as evaluated by cardiac weight, in 7-week-old spontaneous hypertensive rats (SHR). ${ }^{[2]}$ Similarly, 12week-old SHRs develop cardiac hypertrophy when subjected to high salt intake. ${ }^{[3]} \mathrm{LVH}$ significantly contributes to impairment of cardiac systolic and diastolic function with serious implication on hemodynamics. Left ventricular hypertrophy ( $\mathrm{LVH})$ has thus been identified as an important predictor of prognosis in cardiovascular diseases. ${ }^{[4]}$ Hence, reversal or prevention of LVH is an important component of treatment of cardiovascular diseases, directed at reducing morbidity and mortality. ${ }^{[5]}$ Increasing evidence also suggests that salt intake may have a direct effect on LVH independent of blood pressure ${ }^{[6]}$ A review of nine cross-sectional studies showed a close positive cor- 
relation between salt intake and left ventricle mass, with correlation coefficients ranging from 0.22 to $0.61 .^{[7]}$

Presently, the mainstay of treatment modality for $\mathrm{LVH}$ is pharmacotherapy for effective blood pressure control and prevention of cardiovascular changes. These drugs have been reported with varying degrees of success, side effects, and are not always affordable.

Allium sativum is reported to have many biological activities, including protective roles on the cardiovascular system. ${ }^{[8,9]}$ It has been established that garlic has antihypertensive and antioxidant properties. ${ }^{[10-13]}$ Allium species such as onions and garlic are used as foodstuff, condiment, flavoring, and traditional medicine. ${ }^{[14]}$ It is of the onion genus "Allium" and is commonly referred to as garlic. Epidemiologic studies have suggested an inverse relationship between nutritional garlic intake and the occurrence of cardiovascular disorders, and this was attributed to the protective effect of garlic. ${ }^{[15]}$

In many developing countries, a large proportion of the population rely heavily on traditional practitioners and medicinal plants to meet primary health care needs. ${ }^{[16]}$ Many herbs have remained as an alternative to conventional therapy especially in poor areas. ${ }^{[17]}$ Garlic has attracted particular attention of modern medicine due to its widespread health use around the world, and the belief that it helps in maintaining good health, wards off illnesses and provides more vigour. ${ }^{[1]]}$ One of the primary active compounds that gives garlic its characteristic odor and many of its healing benefits is called allicin. In the undamaged clove, over $70 \%$ of the sulphur compounds exists as (+)-S-allyl-L-cysteine sulphoxide or alliin, (+)-S-trans-1-propenyl-L-cysteine sulphoxide or isoalliin and S-methylcysteine sulphoxide or methiin and $\gamma$ glutamyl peptides such as $\gamma$ glutamyl-S-allylcysteine and $\gamma$-glutamyl-S-trans-1-propenyl cysteine. Sulphur is divided approximately $50 \%$ between the cysteine sulphoxides and the $\gamma$ glutamyl peptides. ${ }^{[18]}$ The function of the cysteine sulphoxides is protection, since their breakdown products have antibiotic and fungicidal properties, while the $\gamma$ glutamyl peptides appear to have a storage function for $\mathrm{N}$ and $\mathrm{S}$. The major alkylcysteine sulphoxide in garlic is alliin (85\%), with isoalliin (5\%) and methin (10\%) occupying much more minor roles. ${ }^{[19]}$

Taking into consideration the abundant folkloric evidence in support of antioxidant and cardioprotective potentials of garlic, this study explored the possible protective potential of garlic on high salt diet-induced histomorphological changes in the myocardium of Wistar rats with a view to suggest the application of garlic as an alternative and more affordable therapy relative to the currently available pharmacotherapy in the treatment of cardiovascular disorders associated with cardiac hypertrophy.

\section{Materials and Methods}

\section{Animal care and management}

Twenty-five female Wistar rats weighing 130-180 g obtained from the Animal Holding of Faculty of Basic Medical Sciences, OAU Ile-Ife were used for this study. The rats were randomly assigned into 5 groups of 5 rats each (Groups A, B, C, D and E). They were maintained on standard laboratory rat pellets before the start of the experiment and water was provided ad libitum. The animal handling and care was in line with the rules and guideline of the Health Research and Ethics Committee of the Institute of Public Health, Obafemi Awolowo University Ile-Ife, Nigeria.

\section{Plant material and preparation of extract}

Cloves of garlic bulb were procured from Sabo market in Ile-Ife and identified by a taxonomist in the Department of Botany, OAU, Ile Ife. The raw garlic cloves were peeled, chopped into small pieces and blended. The juice was filtered, and the filtrate was freeze-dried using a lyophilizer and stored in a desiccator. An aliquot portion of the crude extract residue was dissolved in distilled water for administration on each day of the experiment.

\section{Preparation of high salt diet}

High salt diet was prepared by replacing $0.3 \%$ sodium chloride in standard diet formula with $8 \%$ sodium chloride. ${ }^{[20]}$

\section{Animal treatment}

Group A was the control, Group B was negative control, while Groups C, D and E were test groups. Rats in Group A were fed with standard laboratory pellets, while Groups $\mathrm{B}, \mathrm{C}, \mathrm{D}$ and $\mathrm{E}$ were fed on the high-salt diet for five weeks. Thereafter, daily administration of $50 \mathrm{mg} / \mathrm{kg}, 100 \mathrm{mg} / \mathrm{kg}$ and $150 \mathrm{mg} / \mathrm{kg}$ of the garlic extract were given orally to Groups C, D and E respectively for 3 weeks, while rats in Group B received normal saline in place of garlic extract. Oral administration was done, using oral cannula at volume of $0.6 \mathrm{ml} / \mathrm{kg} /$ day.

\section{Sacrifice of animals}

At the end of the experiment, the rats were sacrificed under intramuscular ketamine $(30 \mathrm{mg} / \mathrm{kg})$ anesthesia. The heart was removed for further anatomical studies.

\section{Histological techniques}

Sections of $5 \mu \mathrm{m}$ thickness were cut from the paraffin embedded tissues and stained with haematoxylin and eosin to demonstrate the general histoarchitecture of the heart. ${ }^{[2]}$ Masson's trichrome stain was used to demon- 
strate collagen fibers in the myocardium of the left ventricle of the heart, while Verhoeff -Van Gieson stain was used to demonstrate elastic fibers in myocardium of the left ventricle. ${ }^{[2,23]}$

\section{Determination of relative heart weight (\%)}

At sacrifice, the heart weight was determined using a top loader sensitive balance (Mettler-Toledo Garvens GmbH, Giesen, Germany). The relative weight of the heart (\%) to the body weight at sacrifice was evaluated.

\section{Measurement of serum electrolytes}

Blood samples from each rats was collected separately into clean capped plain tubes and allowed to stand for $30 \mathrm{~min}-$ utes for clotting to occur. These were then centrifuged at 2500 revolution per minutes for 15 minutes. The serum was extracted into clean test tubes for sodium and potassium analysis. This was measured using flame photometry method at wave lengths $590 \mathrm{~nm}$ for sodium and $770 \mathrm{~nm}$ for potassium.

\section{Photomicrography}

Stained sections were viewed under a LEICA research microscope (LEICA DM750, Switzerland) with digital camera attached (LEICA ICC50) and digital photomicrographs were taken at various magnifications.

\section{Measurements of ventricular thickness and lumen diameter}

Photomicrographs of haematoxylin and eosin stained sections were imported on to the Motic Images Plus, Version 2.0 software (Motic China Group Co. Ltd, Shenzhen, China) for histomorphometric analysis, to measure the ventricular thickness and diameter of the cardiomyocytes.

\section{Statistical Analysis}

One-way ANOVA was used to analyze data, followed by Student Newman-Keuls (SNK) test for multiple comparisons. GraphPad Prism 5, Version 5.03 (GraphPad Software, Inc., La Jolla, CA) was used as the statistical package. Statistically significant difference was set at $\mathrm{p}<0.05$.

\section{Results}

One-way ANOVA revealed that, the relative heart weight in the high salt-fed group was lower, though not significant $(\mathrm{p}=0.175)$ than the control group (Table 1). Post hoc analysis showed that serum sodium ion concentration of Group B was significantly higher than the control group $(\mathrm{p}<0.05)$, but was reversed by aqueous garlic extract in Groups C, D and E (Figure 1, Table 2). There
Table 1

Effect of aqueous garlic extract on relative heart weight of rats fed with high salt diet.*

\begin{tabular}{lcc}
\hline Groups & $\begin{array}{c}\text { Absolute heart } \\
\text { weight (g) }\end{array}$ & $\begin{array}{c}\text { Relative heart } \\
\text { weight (\%) }\end{array}$ \\
\hline A (Control) & $0.66 \pm 0.04$ & $0.39 \pm 0.02$ \\
B (High salt diet) & $0.66 \pm 0.1$ & $0.51 \pm 0.06$ \\
C (High salt diet+50 $\mathrm{mg} / \mathrm{kg}$ of AGE) & $0.65 \pm 0.09$ & $0.39 \pm 0.03$ \\
D (High salt diet+100 $\mathrm{mg} / \mathrm{kg}$ of AGE) & $0.78 \pm 0.08$ & $0.43 \pm 0.04$ \\
$\mathrm{E}$ (High salt diet+150 $\mathrm{mg} / \mathrm{kg}$ of AGE) & $0.68 \pm 0.03$ & $0.42 \pm 0.02$ \\
\hline${ }^{*} \mathrm{n}=5$, values are expressed as relative heart mean weight (\%) \pm SEM. $\mathrm{p}<0.05$
\end{tabular}

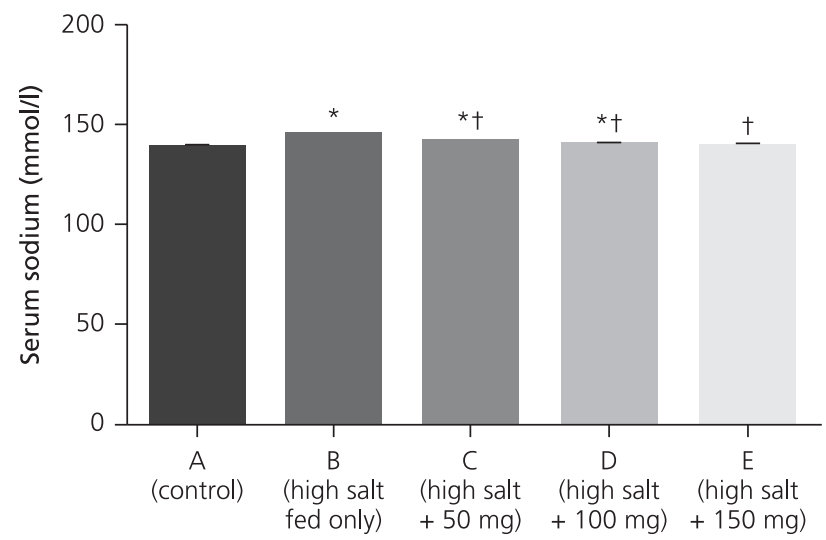

Figure 1. Effect of aqueous garlic extract on serum sodium ion of rats fed with high salt diet $(n=5)$. Values are expressed as serum sodium ( $\mathrm{mmo} / \mathrm{l})$ \pm SEM, * relative to control, trelative to Group B, $p<0.05$.

Table 2

Serum sodium ion concentration in Groups A-D.

\begin{tabular}{lc}
\hline Groups & Serum sodium ion $(\mathrm{mmol} / \mathrm{l}) \pm \mathrm{SEM}$ \\
\hline A & $137.3 \pm 0.42$ \\
B & $144.9 \pm 0.06^{*}$ \\
C & $141.8 \pm 0.19^{\star \dagger}$ \\
D & $141.1 \pm 0.27^{\star \dagger}$ \\
E & $139.1 \pm 0.02^{\dagger}$ \\
\hline
\end{tabular}

was significant difference in serum potassium ion concentration across all experimental groups $\left(\mathrm{F}_{4}, 20=28.54\right.$; $\mathrm{p}<0.05)$. Serum potassium ion concentration of Group B was significantly lower than the control Group $(\mathrm{p}<0.05)$, but was significantly reversed by the aqueous extract in Groups C, D and E (Figure 2, Table 3). A significant difference in thickness of the left ventricular wall was observed across all experimental groups $\left(\mathrm{F}_{4}, 20=140.5\right.$; 


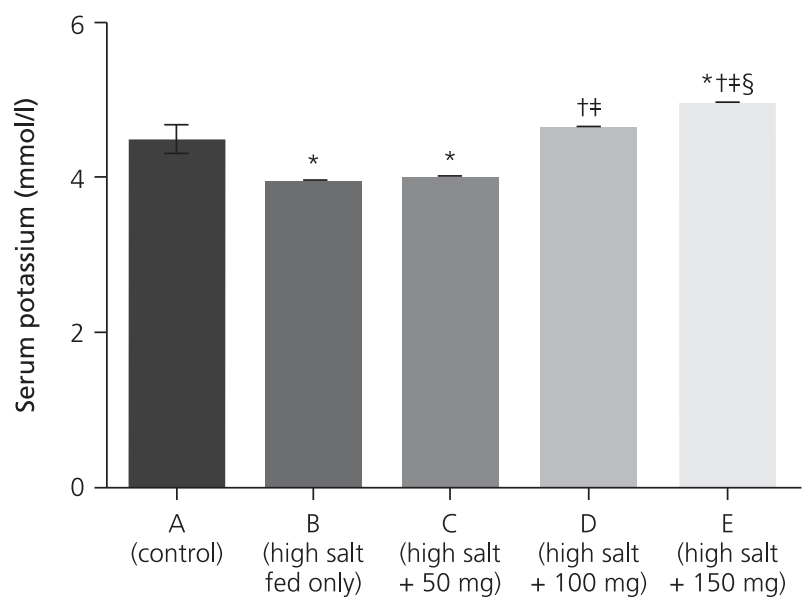

Figure 2. Effect of aqueous garlic extract on serum potassium ion of rats fed with high salt diet. $n=5$, values are expressed as serum potassium $(\mathrm{mmol} / \mathrm{l}) \pm \mathrm{SEM}$, * relative to control, trelative to Group B, *relative to Group C, srelative to Group D, $p<0.05$.

$\mathrm{p}<0.05)$. Post hoc analysis showed that thickness of the left ventricular wall of Group B was significantly higher than the control Group $(\mathrm{p}<0.05)$, but was significantly and dose dependently reversed by aqueous garlic extract in Groups $\mathrm{C}, \mathrm{D}$ and $\mathrm{E}$ (Figure 3, Table 4). Luminal diameter in Group B was significantly lower than the control group $(\mathrm{p}<0.05)$ but was significantly and dose dependently reversed by aqueous garlic extract in Groups C, D and E (Table 5).

\section{Histological findings}

Normal cardiac muscle histology was observed in control rats as shown in Figure 4a. Control rats showed regular arrangement with clear striations of myocardial fibers without histological alterations. In high salt-fed group in Figure $4 b$, the cross-banding pattern of cardiac cells was distorted. Figures $\mathbf{4 d}$ and $\mathbf{4 e}$ showed that cardiac muscles had cross striation similar to control group in Figure 5a. The increase in collagen fibers was evident on histological sections of left ventricle of the rats on a high salt-fed group (Figure $5 \mathbf{b}$ ). The amount of elastic fibers in Figures $\mathbf{6 b}$ and $\mathbf{6 c}$ were reduced when compared with the control group (Figure 6a). In Figures 6d and $\mathbf{6 e}$, there were significant increases in the deposition of elastic fibers as evident in the intense staining intensity.

\section{Discussion}

Histological and histochemical studies of the myocardium of left ventricle and selected serum electrolytes of

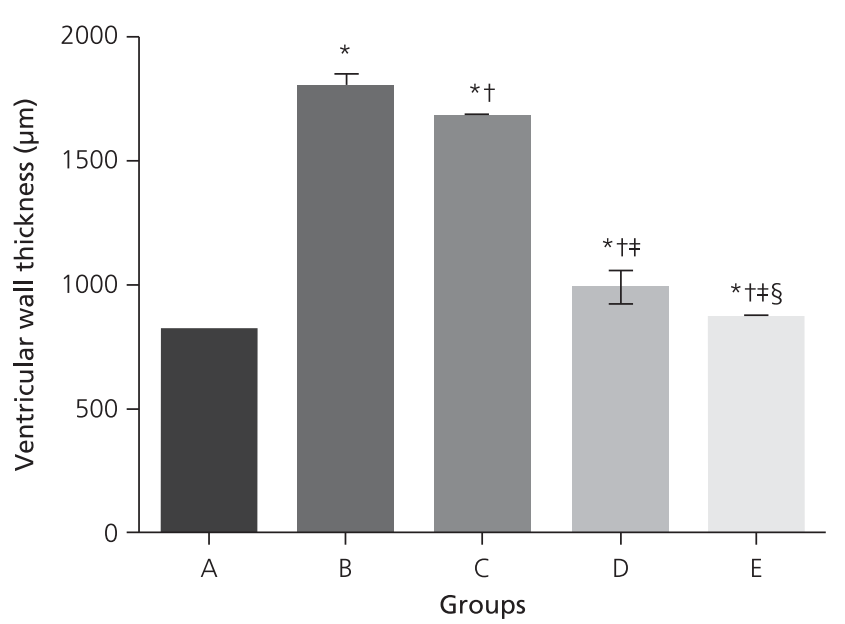

Figure 3. Effect of aqueous garlic extract on left ventricular wall thickness of rats fed with high salt diet. $n=5$, values are in mean $\pm S E M$, * relative to control, trelative to Group B, ‡relative to Group C, Srelative to Group D, $\mathrm{p}<0.05$.

high salt-fed adult $W$ istar rats administered with aqueous extract of garlic were carried out in this study. The thickness of the left ventricle was significantly higher in the high salt-fed group compared to the control group

Table 3

Serum potassium ion concentration in Groups A-D.

\begin{tabular}{lc}
\hline Groups & Serum potassium ion $(\mathrm{mmol} / \mathrm{l}) \pm \mathrm{SEM}$ \\
\hline A & $4.49 \pm 0.18$ \\
B & $3.95 \pm 0.02^{*}$ \\
C & $4.03 \pm 0.02^{*}$ \\
D & $4.67 \pm 0.04^{\dagger \ddagger}$ \\
E & $4.99 \pm 0.02^{* \dagger \ddagger \S}$ \\
\hline
\end{tabular}

Table 4

Effect of aqueous garlic extract on left ventricular lumen diameter of rats fed with high salt diet.

\begin{tabular}{lc}
\hline Groups & $\begin{array}{c}\text { Lumen diameter of the } \\
\text { left ventricle }(\mu \mathrm{m})\end{array}$ \\
\hline A (Control) & $2534 \pm 260.4$ \\
B (High salt diet) & $1717 \pm 18^{*}$ \\
C (High salt diet + $50 \mathrm{mg} / \mathrm{kg}$ of AGE) & $1784 \pm 167.3^{*}$ \\
D (High salt diet + $100 \mathrm{mg} / \mathrm{kg}$ of AGE) & $2175 \pm 227.6^{*} \#$ \\
E (High salt diet + $150 \mathrm{mg} / \mathrm{kg}$ of AGE) & $2386 \pm 214.9^{*} \#$ \\
\hline
\end{tabular}

$n=5$, values are expressed as lumen diameter $(\mu \mathrm{m}) \pm$ SEM of data obtained, * relative to control, ${ }^{+}$relative to Group B, $p<0.05$. 

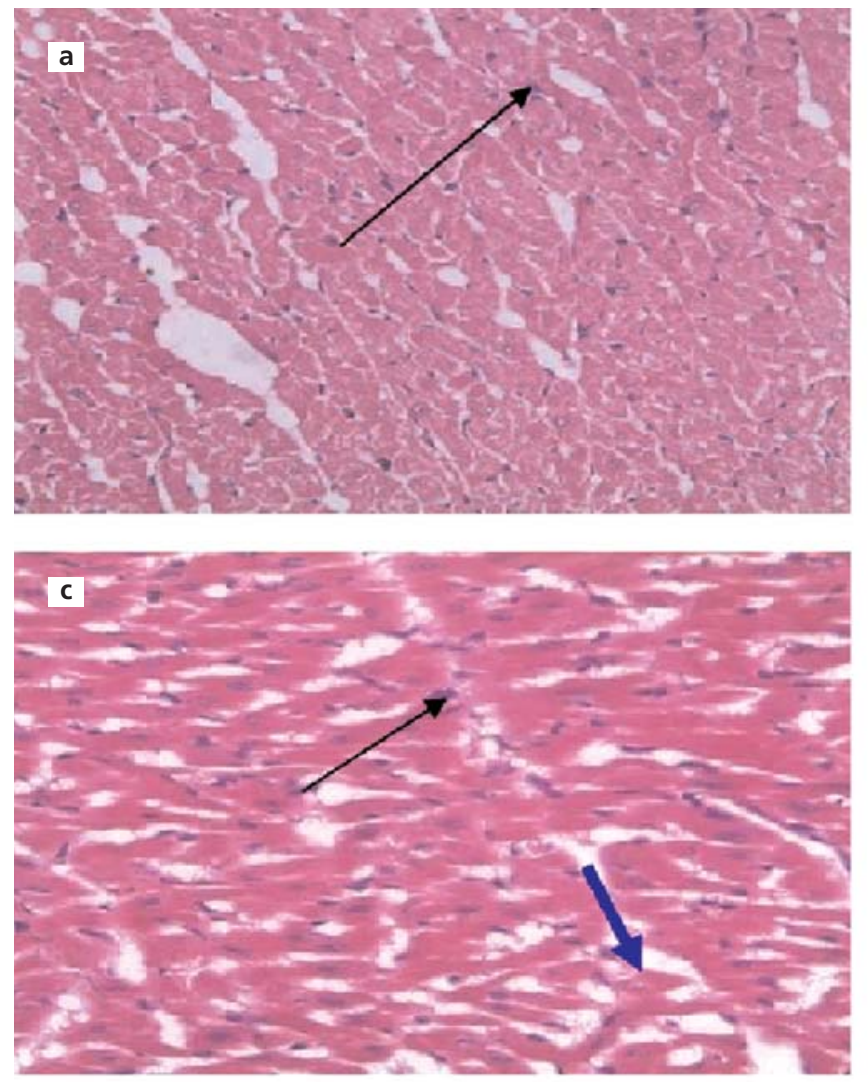

Figure 4. Photomicrograph of transverse section of rat left ventricle. Control (a), high salt-fed only (b), high salt $+50 \mathrm{mg} / \mathrm{kg}$ garlic extract (c), high salt $+100 \mathrm{mg} / \mathrm{kg}$ garlic extract $(\mathbf{d})$, high salt $+150 \mathrm{mg} / \mathrm{kg}$ of garlic extract (e). Black arrows show nucleus of cardiac muscle cell, blue arrows show the interstitial connective tissue and red arrow shows branching of cardiomyocytes (Haematoxylin and eosin stain $\times 400$ ). [Color figure can be viewed in the online issue, which is available at www.anatomy.org.tr]

$(\mathrm{p}<0.05)$. The micrograph of the control group showed normal histology of the heart, with regular arrangement of clear striation of myocardial fibers without histological alterations; however, the cardiac cells became distorted following administration of high salt diet. In this study, the relative heart weight of the high salt-fed group was higher than the control group, though the level of difference was not statistically significant $(\mathrm{p}=0.175)$. This may be attributable to the relatively small sample size used in this study. Similarly, the serum sodium was significantly higher in the high salt-fed group than the con-
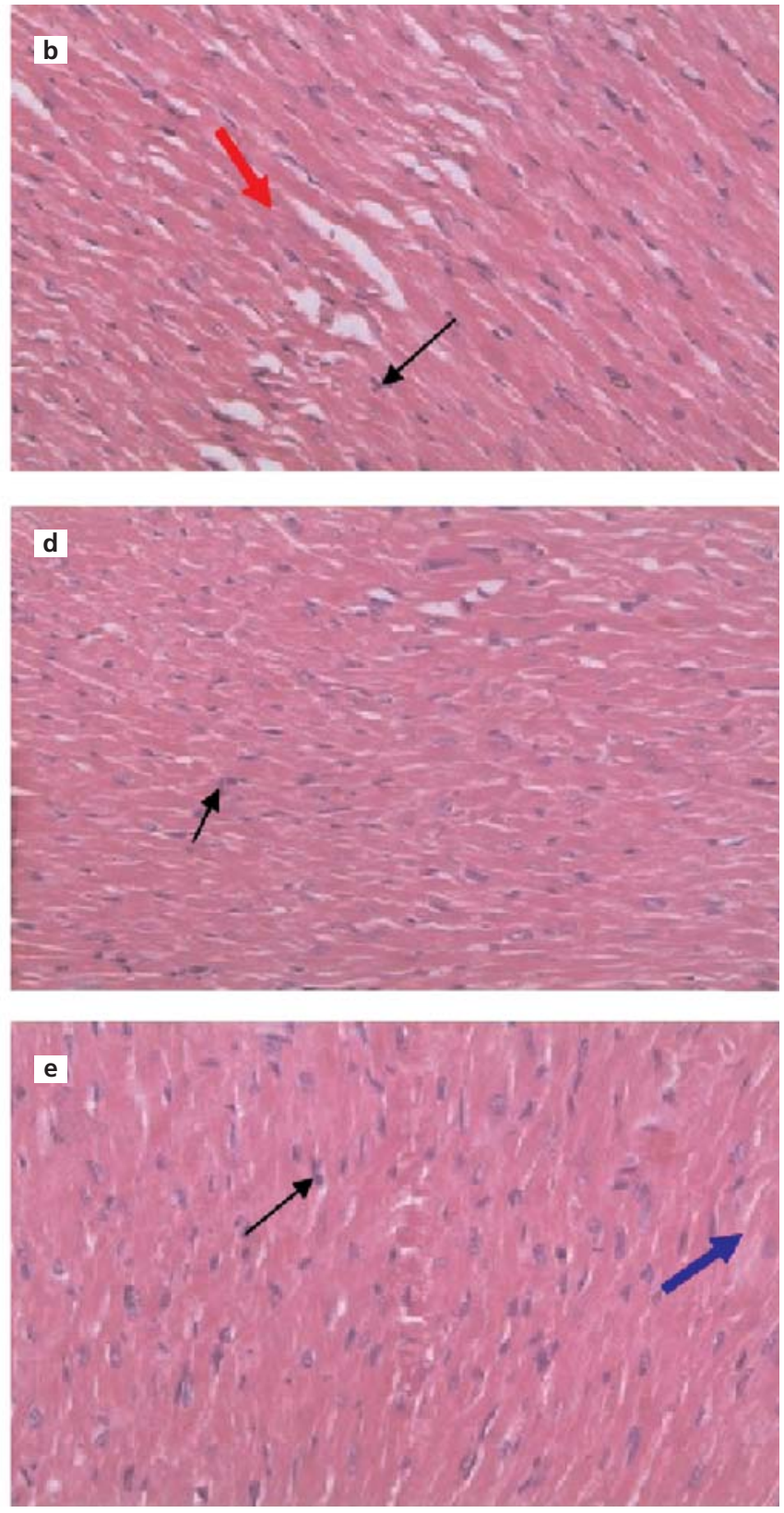

trol group $(\mathrm{p}<0.05)$. This suggests that high salt diet resulted in hypernatriemia, myocardial damage and hypertrophy of the ventricular wall. This is in agreement with previous reports showing that high salt intake induced $\mathrm{LVH}^{\left[{ }^{[2]}\right.}$ While some studies have linked the high salt diet-induced hypertrophy to salt-induced hypertension, others have shown that the hypertrophy is independent of high blood pressure. ${ }^{[1,25]}$ In normotensive rats, a high salt diet did not increase blood pressure even when there was significant cardiac hypertrophy. ${ }^{[26]}$ Increasing evidence from multiple clinical studies 

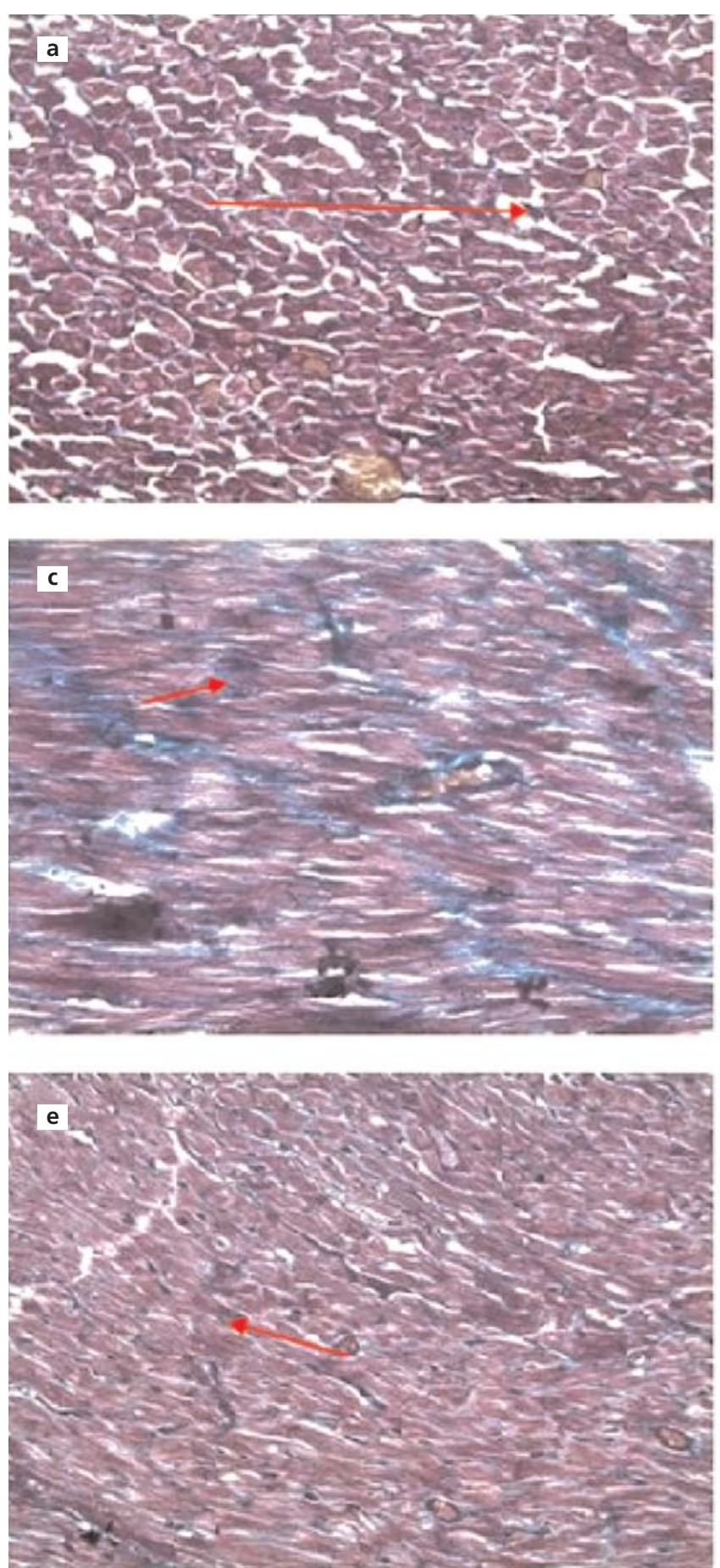

showed that excess salt intake was related to cardiovascular organ damage, independent of blood pressure. ${ }^{[27]}$ The pathophysiological mechanisms responsible for high salt diet-induced hypertrophy remain debatable.

The active ingredient in garlic extract is known as allicin (diallyl thiosulfinate) which is mainly organosulfur and has been shown to inhibit the renin-angiotensin-
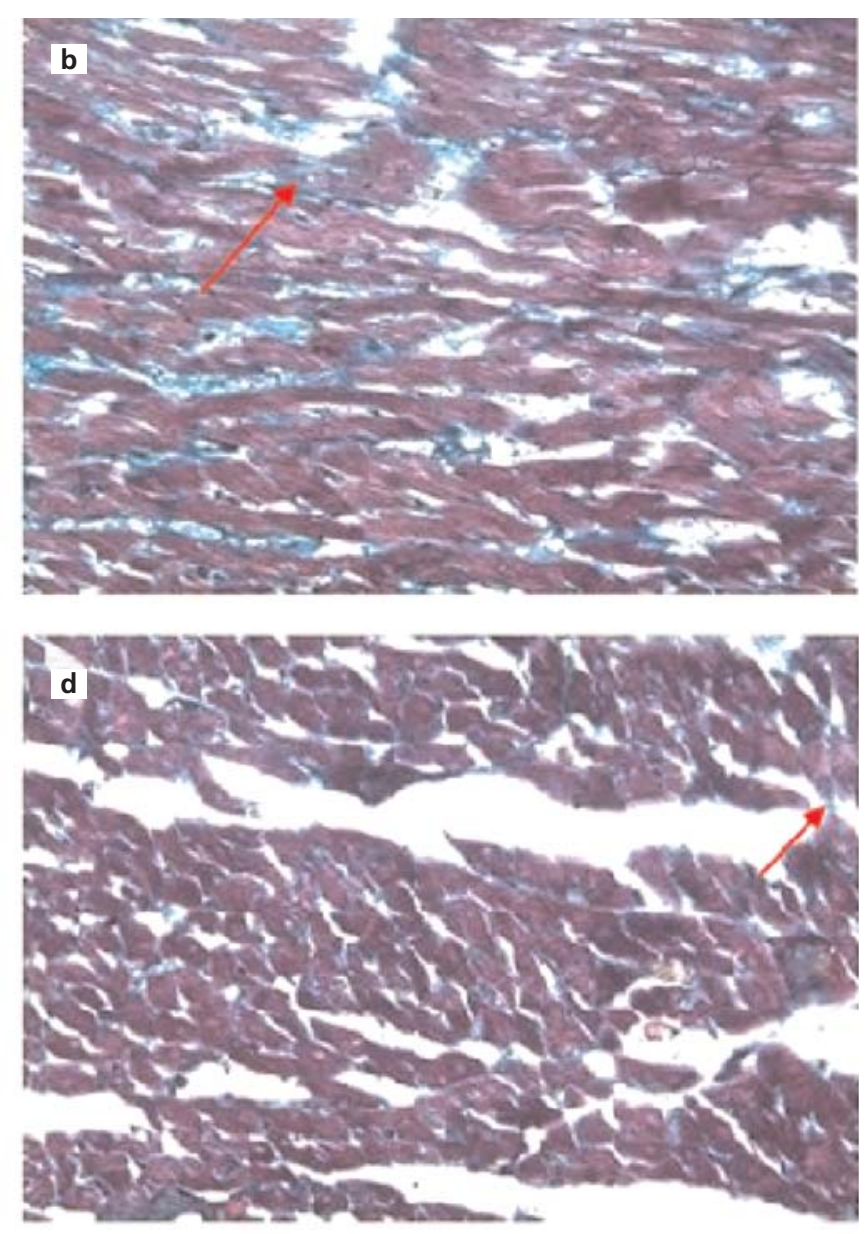

Figure 5. Photomicrograph of transverse section of a rat left ventricle. Control (a), high salt-fed only (b), high salt $+50 \mathrm{mg} / \mathrm{kg}$ garlic extract (c), high salt $+100 \mathrm{mg} / \mathrm{kg}$ garlic extract $(\mathbf{d})$, high salt $+150 \mathrm{mg} / \mathrm{kg}$ of garlic extract (e). Red arrows indicate collagen deposits (Masson's trichrome stain $\times 400$ ). [Color figure can be viewed in the online issue, which is available at www.anatomy.org.tr]

aldosterone system and prostaglandin synthesis. ${ }^{[28]}$ Garlic was reported to exhibit potent angiotensin converting enzyme (ACE) inhibitory activity. ${ }^{[29]}$ The reversal of high salt diet-induced myocardial distortion, ventricular hypertrophy can be explained by the ACE inhibitory activity of the garlic extract. The reduction in ACE activity results in reduction in plasma level of angiotensin II (a known 

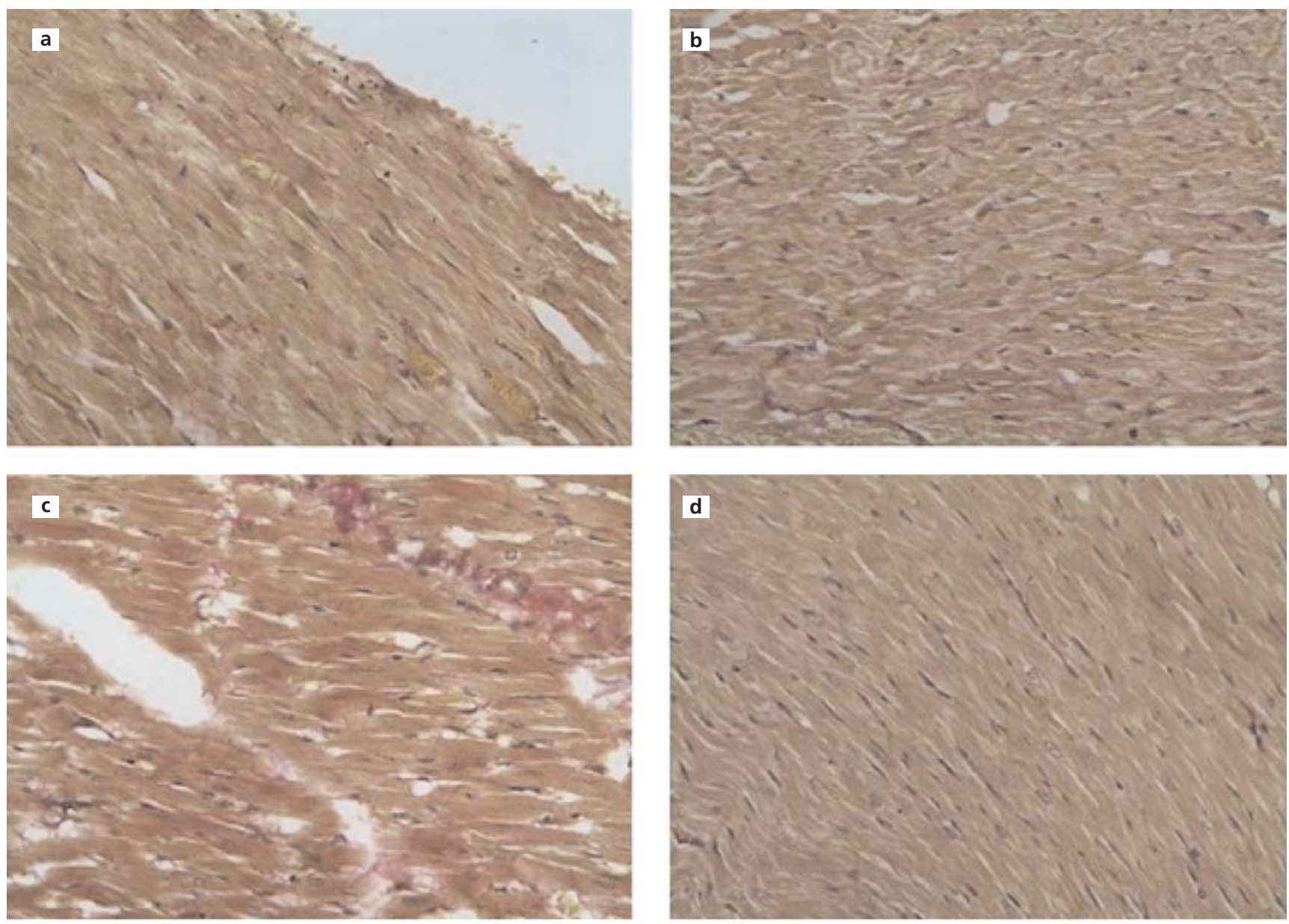

Figure 6. Photomicrograph of transverse section of a rat left ventricle. Control (a), high salt-fed only (b), high salt $+50 \mathrm{mg} / \mathrm{kg}$ garlic extract (c), high salt $+100 \mathrm{mg} / \mathrm{kg}$ garlic extract (d), high salt $+150 \mathrm{mg} / \mathrm{kg}$ of garlic extract (e). Structures with black pigmentation are elastic fibers (Verhoeff -Van Gieson stain $\times 400$ ). [Color figure can be viewed in the online issue, which is available at www.anatomy.org.tr]

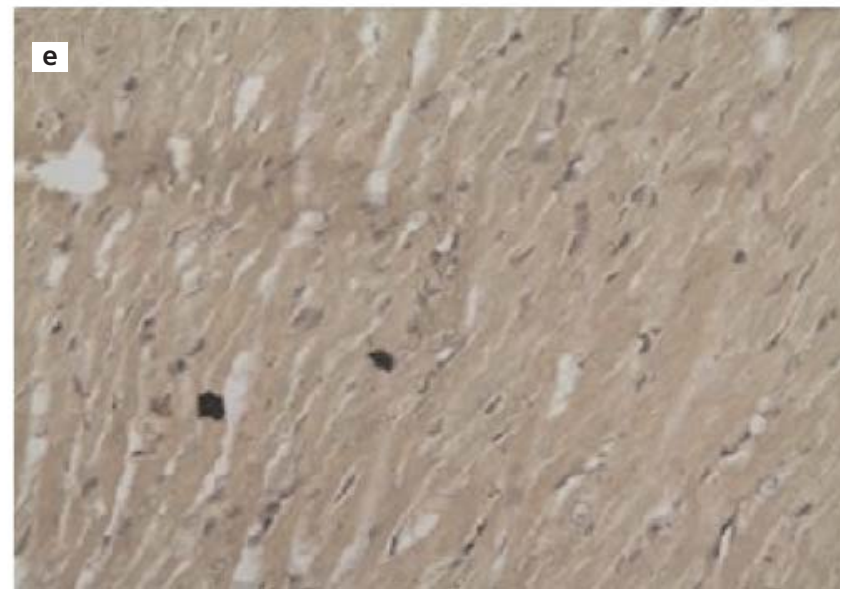

potent vasoconstrictor). Angiotensin II is also known to cause cardiovascular changes and sodium ion retention through stimulation of release of aldosterone. ${ }^{[30,31]}$ Garlic extract-induced inhibition of ACE probably leads to reduction in angiotensin II, leading to decreased adrenal production of aldosterone. ${ }^{[32]}$ This reduction in aldosterone production ultimately decreases the reabsorption of sodium and water from distal convoluted renal tubule, resulting in natriuresis and thereby decreasing plasma volume. $^{[32]}$ The garlic extract-induced reduction of plasma level of angiotensin II followed by natri- and diuresis may be responsible for the reversal of the high salt-induced ventricular hypertrophy reported in this study. This result is similar to other reports in which high-salt diet induced 
cardiac hypertrophy in rats was inhibited by spironolactone. ${ }^{[26]}$ Another, evidence is increased distribution of collagen fibers in the left ventricle of the high salt-fed group which was reversed by the garlic extract.

\section{Conclusion}

The results of this study indicate that high salt diet causes significant histomorphological changes on myocardium of the left ventricle of rats as evidenced by myocardiocyte distortion and ventricular hypertrophy. Garlic extract has protective and ameliorative properties on these high salt diet-induced changes in the cardiovascular system probably via inhibition of renin-angiotensinaldosterone system. Further studies on the effect of garlic extract on natriuresis and markers of activity of reninangiotensin-aldosterone system will be required to support this suggestion.

\section{References}

1. Ahn J, Jasmina V, Michel S, Dinko S, Edward DF. Cardiac structural and functional responses to salt loading in SHR. Am J Physiol Heart Circ Physiol 2004;287:H767-72.

2. Susic D, Jasmina V, Frohlich E. Cardiovascular effects of inhibition of rennin-angiotensin-aldosterone system components in hypertensive rats given salt excess. Am J Physiol Heart Circ Physiol 2010;298: $1177-81$.

3. Ziegelhöffer-Mihalovicova B, Arnold N, Marx G, Tannapfel A, Zimmer HG, Rassler B. Effects of salt loading and various therapies on cardiac hypertrophy and fibrosis in young spontaneously hypertensive rats. Life Sci 2006;79:838-46.

4. Levy D, Garrison RJ, Savage DD, Kannel WB, Castelli WP. Prognostic implications of echocardiographically determined left ventricular mass in the Framingham Heart Study. N Engl J Med 1990;322:1561-6.

5. Devereux RB, Dahlof B, Gerdts E, Boman K, Nieminen MS, Papademetriou V, Rokkedal J, Harris KE, Edelman JM, Wachtell K. Regression of hypertensive left ventricular hypertrophy by losartan compared with atenolol: the Losartan Intervention for Endpoint Reduction in Hypertension (LIFE) trial. Circulation 2004;110: 1456-62.

6. Burnier M, Phan O, Wang Q. High salt intake: a cause of blood pressure-independent left ventricular hypertrophy? Nephrol Dial Transplant 2007;22:2426-9.

7. Messerli FH, Schmieder RE, Weir MR. Salt. A perpetrator of hypertensive target organ disease? Arch Intern Med 1997;157:2449-52.

8. Yeh YY, Yeh SM. Homocysteine-lowering action is another potential cardiovascular protective factor of aged garlic extract. J Nutr 2006;136:745-9S.

9. Mukherjee S, Lekli I, Goswami S, Das DK. Freshly crushed garlic is a superior cardioprotective agent than processed garlic. J Agric Food Chem 2009;57:7137-7.

10. Harauma A, Moriguchi T. Aged garlic extract improved blood pressure in spontaneously hypertensive rats more safely than raw garlic. J Nutr 2006;136:769-73S.
11. Reinhart KM, Coleman CI, Teevan C, Vachhani P, White CM. Effects of garlic on blood pressure in patients with and without systolic hypertension: a meta-analysis. Ann Pharmacother 2008;42: 1766-71.

12. Ried K, Frank OR, Stocks NP, Fakler P, Sullivan T. Effect of garlic on blood pressure: a systematic review and meta-analysis BMC Cardiovasc Disord 2008;8:13.

13. Dhawan V, Jain S. Garlic supplementation prevents oxidative DNA damage in essential hypertension. Mol Cell Biochem 2005;275:8594.

14. Banerjee SK, Maulik SK. Effect of garlic on cardiovascular disorders: a review. Nutr J 2002;1:4.

15. Reuter HD. Allium sativum and Allium ursinum. Part 2 pharmacology and medicinal application. Phytomedicine 1995;2:73-91.

16. World Health Report. Monographs on selected medicinal plants. Geneva (Switzerland): World Health Organisation 1999;1:295.

17. Sánchez de Medina F, Gámez MJ, Jiménez I, Jiménez J, Osuna JI, Zarzuelo A. Hypoglycemic activity of juniper "berries". Planta Med 1994;60:197-200.

18. Mütsch-Eckner M, Meier B, Wright AD, Sticher O. Gamma-glutamyl peptides from allium sativum bulbs. Phytochemistry 1992;31: 2389-91

19. Lawson LD. The composition and chemistry of garlic cloves and processed garlic. In: Koch HP, Lawson LD, editors. The science and therapeutic application of allium sativum. Baltimore (MD): Williams and Wilkins; 1996. p. 37-107

20. Obiefuna PC, Obiefuna IP. Salt-induced hypertension in rats alters the response of isolated aortic rings to cromakalim. West Indian Med J 2001;50:17-21.

21. Drury RA, Wallington EA. Carleton's histological technique. 5th ed. New York: Oxford University Press; 1980. pp. 188-9, 237-40, 290-1.

22. Masson, P. Some histological methods. Trichrome stainings and their preliminary technique. Bulletin of the International Association of Medicine. J Tech Methods 1929;12:75.

23. Verhoeff FH. Some new staining methods of wide applicability. Including a rapid differential stain for elastic tissue. JAMA 1908;50: 876.

24. Resende MM, Mill JG. Effect of high salt intake on local reninangiotensin system and ventricular dysfunction following myocardial infarction in rats. Clin Exp Pharmacol Physiol 2007;34:274-9.

25. Matavelli LC, Zhou X, Varagic J, Susic D, Frohlich ED. Salt loading produces severe renal hemodynamic dysfunction independent of arterial pressure in spontaneously hypertensive rats. Am J Physiol Heart Circ Physiol 2006;292:814-9.

26. Cordaillat M, Rugale C, Casellas D, Mimran A, Jover B. Cardiorenal abnormalities associated with high sodium intake: correction by spironolactone in rats. Am J Physiol Regul Integr Comp Physiol 2005;289:R1137-43.

27. Du Cailar G, Ribstein J, Daures JP, Mimran A. Sodium and left ventricular mass in untreated hypertensive and normotensive subjects. Am J Physiol Heart Circ Physiol 1992;263:H177-81.

28. Banerjee SK, Mukherjee PK, Maulik SK. Garlic as an antioxidant: the good, the bad and the ugly. Phytother Res 2003;17:97-106.

29. Sharifi AM, Darabi R, Akbarloo N. Investigation of antihypertensive mechanism of garlic in $2 \mathrm{~K} 1 \mathrm{C}$ hypertensive rat. J Ethnopharmacol 2003;86:219-24. 
30. Irani K. Angiotensin II-stimulated vascular remodeling: the search for the culprit oxidase. Circ Res 2001;88:858-60.

31. Varagic J, Frohlich ED, Susic D, Ahn J, Matavelli L, Lopez B, Díez J. AT1 receptor antagonism attenuates target organ effects of salt excess in SHRs without affecting pressure. Am J Physiol Heart Circ Physiol 2008;294:853-8.

32. Palmer BF. Managing hyperkalemia caused by inhibitors of the rennin-angiotensin aldosterone system. N Engl J Med 2004;351:585- 92.

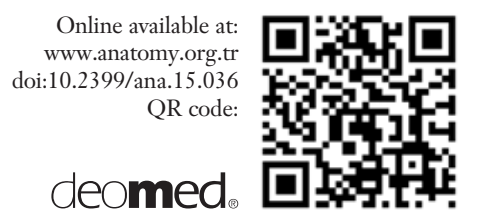

Correspondence to: Olusola Stephen Saka, MSc

Faculty of Basic Medical Sciences, Obafemi Awolowo University,

Ile-Ife, Osun-State, Nigeria

Phone: +234806 7646211

e-mail: olusolasaka1@gmail.com

Conflict of interest statement: No conflicts declared.

This is an open access article distributed under the terms of the Creative Commons Attribution-NonCommercial-NoDerivs 3.0 Unported (CC BY-NCND3.0) Licence (http://creativecommons.org/licenses/by-nc-nd/3.0/) which permits unrestricted noncommercial use, distribution, and reproduction in any medium, provided the original work is properly cited. Please cite this article as: Saka OS, Komolafe AO, Ogunlade O, Owolabi AR, Olayode AA, Arayombo BE. Effects of aqueous extract of garlic (Allium sativum) on the left ventricle myocardium of high salt-fed adult Wistar rats. Anatomy 2016;10(1):21-29. 